\title{
Bearing Strength Formula of Roughened Concrete Considering Vertical Projection Area
}

\author{
Ukyo Musya $^{1}$, Yuki Katagiri ${ }^{1}$, Yuya Takase ${ }^{2 *}$, Takahide Abe $^{3}$, Keita Sakamoto ${ }^{3}$, \\ Takeshi Hiwatashi $^{4}$ and Keichi Katori ${ }^{5}$
}

\begin{abstract}
When buildings are seismically retrofitted, new members are connected to existing members through a roughened concrete surface, which is created using a vibration drill. However, there are few studies on such roughened concrete. When the roughened concrete area ratio is small, bearing failure occurs. On the other hand, shear failure occurs when the roughened concrete area ratio is large. In this paper, the focus was on bearing failure. When the roughened concrete area ratios were 0.1 to 0.3 , the failure mode was bearing failure. To evaluate shear strength, the shapes of roughened concrete were measured using a laser displacement sensor and 3D scanner. Moreover, shear loading tests were conducted. Finally, a shear strength formula was proposed considering the concrete compressive strength, Young's modulus, and vertical projection area. By comparing the test results with the calculated values, it is concluded that the proposed formula estimated the test results well. Finally, this paper is an extension of the authors' previous work [Musya et al., (2019). "Supported Strength Formula of Roughened Concrete Using Shape Measurement Value by 3D-scanner." AIJ Journal of Technology and Design, 25(59), 55-60].
\end{abstract}

\section{Introduction}

When buildings undergo seismic retrofitting, strengthening members are connected to existing members by roughening concrete surfaces (which are made through a chipping process using a vibration drill), and by applying post-installed anchors. On the roughened concrete surface, shear force is transferred by the local uneven surface. However, the shape of roughened concrete (such as the area or depth of the roughened concrete) depends on the technique and focus of the construction worker. Because it is difficult to manage the shape of roughened concrete, there are no theoretical regulations concerning roughened concrete in joint design (JBDPA 2017). However, it was pointed out that an estimation method of the shear strength of roughened concrete is required (Isozaki et al. 2017, 2018).

Studies on shear stress transfer mechanisms in cracked concrete have been conducted (Maekawa et al. 1997, and

${ }^{1}$ Graduate student, Division of Sustainable and Environmental Engineering, Muroran Institute of Technology, Japan.

${ }^{2}$ Associate professor, College of Environmental Technology, Muroran Institute of Technology, Japan.

*Corresponding author,

E-mail: y.takase@mmm.muroran-it.ac.jp

${ }^{3}$ Chief, Seismic Solution Department, Tobishima Corporation, Japan.

${ }^{4}$ Senior Researcher, Research and Development Center, Toa Corporation, Japan.

${ }^{5}$ Professor, Department of Architecture, Faculty of Science and Engineering, Toyo University, Japan. others). In addition, the relation between the concrete fracture surface and shear strength was investigated (Satoh et al. 2014, and others). Moreover, shear strength formulas for shear keys in a reinforced-concrete joint surface have been proposed (Abe et al. 2017; Rahal 2010; Nakano 2000, and others).

However, there are few studies on the shear strength of roughened concrete produced with a vibration drill for retrofitted structures. The authors conducted shear loading tests and modeling (Isozaki et al. 2017, 2018) with the roughened concrete area ratio $r_{c r}$ (the ratio of joint surface area $A_{j}$ to the horizontal projection area of roughened concrete area $A_{c r}$ ) set to 0.1 to 0.75 . The failure mode of the specimens with $r_{c r}=0.1$ to 0.3 was bearing failure. The failure mode of the specimens with $r_{c r}=0.5$ and 0.75 was shear failure.

There are a number of guidelines for seismic retrofitting of buildings. According to these guidelines, $r_{c r}$ is set to $0.15-0.75$ (JBDPA 2017, and others). Furthermore, the shear strengths are almost the same value when $r_{c r}$ set to a value of 0.3 and more, based on experimental tests. Therefore, it is important to evaluate the shear strength of bearing failure for practical design. In previous studies (Isozaki et al. 2017, 2018), mechanical behavior was modeled for bearing failure. However, because this model is too difficult to use for structural design, the authors have attempted to construct a shear strength formula.

The vertical projection area of roughened concrete likely influences the maximum stress for bearing failure. In previous studies (Isozaki et al. 2017, 2018), three-dimensional coordinate data measurement of a roughened surface was conducted using a shape measurement setup with a high-sensitivity spot displacement 
Table 1 Shear loading test specimen parameters.

\begin{tabular}{|c|c|c|c|c|}
\hline Specimen & Area ratio of roughening & Measured area ratio & Target value of $f_{C}$ & Depth type \\
\hline $\mathrm{CH}-10 \mathrm{NL}$ & \multirow{4}{*}{0.100} & 0.154 & $10(\mathrm{~L})$ & Normal \\
\hline CH-10NM & & 0.099 & $20(\mathrm{M})$ & Normal \\
\hline CH-10DM & & 0.117 & $20(\mathrm{M})$ & Deep \\
\hline $\mathrm{CH}-10 \mathrm{NH}$ & & 0.137 & $30(\mathrm{H})$ & Normal \\
\hline CH-20NL & \multirow{4}{*}{0.200} & 0.212 & $10(\mathrm{~L})$ & Normal \\
\hline CH-20NM & & 0.213 & $20(\mathrm{M})$ & Normal \\
\hline CH-20DM & & 0.182 & $20(\mathrm{M})$ & Deep \\
\hline $\mathrm{CH}-20 \mathrm{NH}$ & & 0.190 & $30(\mathrm{H})$ & Normal \\
\hline $\mathrm{CH}-30 \mathrm{NL}$ & \multirow{4}{*}{0.300} & 0.288 & $10(\mathrm{~L})$ & Normal \\
\hline CH-30NM & & 0.290 & $20(\mathrm{M})$ & Normal \\
\hline CH-30DM & & 0.308 & $20(\mathrm{M})$ & Deep \\
\hline $\mathrm{CH}-30 \mathrm{NH}$ & & 0.297 & $30(\mathrm{H})$ & Normal \\
\hline
\end{tabular}

sensor (here, this is called a "laser displacement sensor") and steel frame with a linear motion guide.

However, it is very difficult to attach such a setup on actual members owing to the fact that the laser displacement sensor can move freely in two directions on the roughened surface. Moreover, the measurement time is too long; for example, it took between $6 \mathrm{~h}$ and $12 \mathrm{~h}$ to measure a single specimen. In recent years, the accuracy of three-dimensional coordinate data measurement has become high and this method of measurement is now being applied also in the civil engineering field. Various measuring devices that can acquire highly accurate 3D coordinates from a distance in a short time have been developed. For example, 3D scanners, which are one such type of device, can be applied to the construction management of buildings.

Although they allow highly accurate measurement, 3D scanners are not usually employed for measurement of small-sized objects with a resolution of approximately

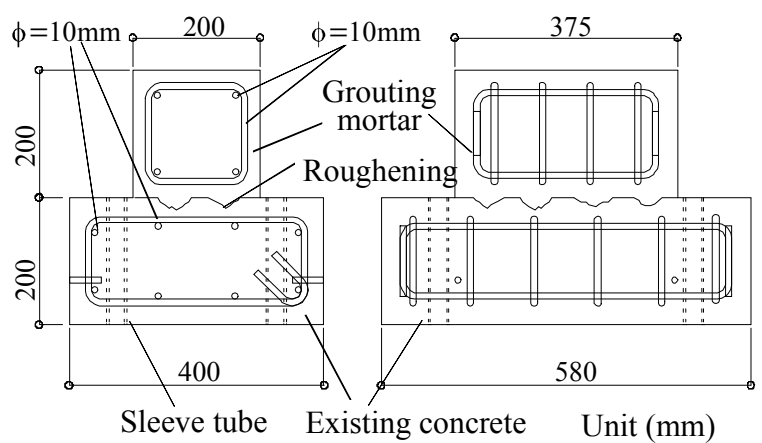

(a) Shear-loading test

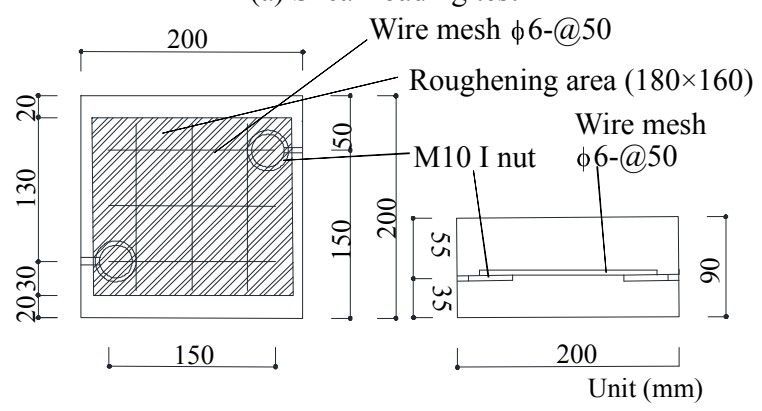

(b) Shape measurement

Fig. 1 Specification dimensions of specimens.
$0.1 \mathrm{~mm}$, but rather for measurement of entire objects, members, or structures. Thus, 3D scanners may not be suitable for measurement of roughened concrete. The data obtained by laser displacement sensors are more accurate. Therefore, in this study, the roughened concrete shape was measured by using two measurement methods: the laser displacement sensor used in the authors' previous studies, and a 3D scanner that can be applied to existing buildings. By comparing the two types of measured data, the applicability and measuring accuracy of 3D scanners for roughened concrete was investigated. In addition, shear loading tests were carried out on specimens with $r_{c r} \leq 0.3$, for which bearing failure is considered to be the dominant mode of failure, and construction of a shear strength formula considering the vertical projection area was aimed for as the purpose of this study.

\section{Outline of tests on roughened concrete surface}

To investigate the bearing strength of roughened concrete, shape measurement and shape analysis were conducted by two measurement methods, namely the laser displacement sensor measurement method and the 3D scanner measurement method. The tests are outlined below.

\subsection{Specimen specifications and test parame- ters}

Two types of specimen were prepared, one for the shear loading test and the other for the shape measurement test. As each type of test was performed in a different location, thus necessitating the transport of specimens, the authors designed the shape measurement specimen for ease of transport. Figure 1 shows the specification dimensions of the specimens. Tables $\mathbf{1}$ and $\mathbf{2}$ list the test specimen parameters used in the tests. The specimens used in the shear loading test were rectangular blocks with dimensions of $580 \times 400 \times 200 \mathrm{~mm}$. An area of 375 $\times 200 \mathrm{~mm}$ was roughened as the test area. The shape measurement test specimens were rectangular in shape with dimensions of $200 \times 200 \times 90 \mathrm{~mm}$. The joint surface was an area of $180 \times 160 \mathrm{~mm}$ on the top surface. 
Table 2 Shape measurement test specimen parameters.

\begin{tabular}{|c|c|c|c|c|c|c|c|c|c|}
\hline \multirow[b]{2}{*}{ Specimen } & \multirow{2}{*}{$\begin{array}{l}\text { Area ratio of } \\
\text { roughening }\end{array}$} & \multirow{2}{*}{$\begin{array}{l}\text { Measured } \\
\text { area ratio }\end{array}$} & \multirow{2}{*}{$\begin{array}{l}\text { Depth } \\
\text { type }\end{array}$} & \multicolumn{3}{|c|}{ Laser displacement sensor } & \multicolumn{3}{|c|}{ 3D scanner } \\
\hline & & & & $D_{\max }$ & $A_{H c r}$ & $\begin{array}{c}\text { Average } \\
\text { of } A_{H c r}\end{array}$ & $D_{\max }$ & $A_{H c r}$ & $\begin{array}{c}\text { Average } \\
\text { of } A_{H c r}\end{array}$ \\
\hline SCH-10NL & \multirow{4}{*}{0.100} & 0.113 & Normal & 15.0 & 2066 & \multirow{4}{*}{1845} & 14.8 & 2372 & \multirow{4}{*}{2348} \\
\hline SCH-10NM & & 0.115 & Normal & 11.7 & 1665 & & 11.9 & 2355 & \\
\hline SCH-10DM & & 0.075 & Deep & 17.7 & 1811 & & 20.6 & 2352 & \\
\hline SCH-10NH & & 0.112 & Normal & 11.7 & 1838 & & 10.6 & 2312 & \\
\hline SCH-20NL & \multirow{4}{*}{0.200} & 0.188 & Normal & 16.2 & 2567 & \multirow{4}{*}{2668} & 16.5 & 3409 & \multirow{4}{*}{3295} \\
\hline SCH-20NM & & 0.204 & Normal & 13.7 & 2512 & & 13.7 & 3134 & \\
\hline SCH-20DM & & 0.206 & Deep & 17.5 & 2983 & & 18.3 & 3430 & \\
\hline SCH-20NH & & 0.192 & Normal & 12.7 & 2609 & & 12.5 & 3207 & \\
\hline SCH-30NL & \multirow{4}{*}{0.300} & 0.332 & Normal & 14.9 & 3333 & \multirow{4}{*}{3118} & 14.9 & 4306 & \multirow{4}{*}{4061} \\
\hline SCH-30NM & & 0.292 & Normal & 12.6 & 2968 & & 12.8 & 4349 & \\
\hline SCH-30DM & & 0.290 & Deep & 18.1 & 3342 & & 25.1 & 3808 & \\
\hline SCH-30NH & & 0.293 & Normal & 13.5 & 2829 & & 13.8 & 3779 & \\
\hline
\end{tabular}

$D_{\max }:$ Maximum depth (mm), $A_{H c r}$ : Vertical projection area $\left(\mathrm{mm}^{2}\right)$.

Table 3 Material properties of concrete and grouting mortar.

\begin{tabular}{|c|c|c|c|c|}
\hline Specimen & Material & $f_{C}$ or $f_{G} \quad\left(\mathrm{~N} / \mathrm{mm}^{2}\right)$ & $E_{C}\left(\mathrm{kN} / \mathrm{mm}^{2}\right)$ & $f_{t}\left(\mathrm{~N} / \mathrm{mm}^{2}\right)$ \\
\hline \multirow{2}{*}{$\mathrm{CH}-10,20,30 \mathrm{NL}$} & Concrete & 7.9 & 14.6 & 1.10 \\
\hline & Grouting mortar & 72.3 & 24.4 & 4.10 \\
\hline \multirow{2}{*}{ CH-10, 30NM } & Concrete & 17.1 & 24.7 & 1.83 \\
\hline & Grouting mortar & 64.6 & 26.2 & 2.10 \\
\hline \multirow{2}{*}{$\begin{array}{c}\text { CH-20NM, } \\
\text { CH-10, } 20 \text { 30DM }\end{array}$} & Concrete & 19.9 & 29.1 & 1.90 \\
\hline & Grouting mortar & 68.7 & 26.3 & 3.42 \\
\hline \multirow{2}{*}{$\mathrm{CH}-10,20,30 \mathrm{NH}$} & Concrete & 31.7 & 30.1 & 2.50 \\
\hline & Grouting mortar & 72.3 & 24.4 & 4.10 \\
\hline
\end{tabular}

$f_{C}$ : Compressive strength of concrete, $f_{G}$ : Compressive strength of grouting mortar, $E_{C}$ : Young's modulus,

$f_{t}$ : $\quad$ Splitting strength

The test parameters were roughened concrete surface ratio $r_{c r}$, roughened concrete depth, and concrete compressive strength $f_{C}$. Three values for $r_{c r}$ were tested, 0.1 , 0.2 , and 0.3. Specimens with two different roughening depths were prepared, and the target compression strength $f_{C}$ was set to 10,20 , and $30 \mathrm{~N} / \mathrm{mm}^{2}$.

In the shear loading test, one specimen was used for each parameter. For the shape measurement test, three specimens were prepared for each parameter. Then, the average value of the three specimens was used for the shape analysis. Although there was only one specimen for each parameter in the shear loading test, the total number of specimens for each $r_{c r}$ value was four specimens. Use of the average of the values obtained for each $r_{c r}$ was opted for to yield quantitative data. This would also have the advantage of rendering insignificant random variations in shape properties and thus be useful for the quantitative evaluation of shear strength.

The specimen name consists of the letters $\mathrm{CH}$ for the loading test specimens or $\mathrm{SCH}$ for the shape measurement test specimens, followed by a two-digit number indicating the area ratio, a symbol indicating depth $(\mathrm{N}$ : normal, D: deep), and a symbol indicating concrete strength $\left(\mathrm{L}: f_{C}=10 \mathrm{~N} / \mathrm{mm}^{2}, \mathrm{M}: f_{C}=20 \mathrm{~N} / \mathrm{mm}^{2}, \mathrm{H}: f_{C}=30\right.$ $\mathrm{N} / \mathrm{mm}^{2}$ ). The lists of test parameters are shown in Tables 1 and 2. Table 2 shows a comparison of the maximum depths for different $r_{c r}$ values, but there was little difference in maximum depth values.
In these tables, the target roughened areas and measured values of $r_{c r}$ from the image analysis are also listed. Table 3 lists the material properties of the concrete and grouting mortar. The same concrete as for the shear loading test was used for the measurement specimens. The joint surface was roughened with a vibration drill, $r_{c r}$ being determined by image analysis. First, black paint was applied to a smooth concrete surface. Then, the concrete was roughened, and image analysis was done, checking $r_{c r}$ by the difference in color between the black painted state and the roughened state. By checking the image analysis results, $r_{c r}$ was adjusted to the target value.
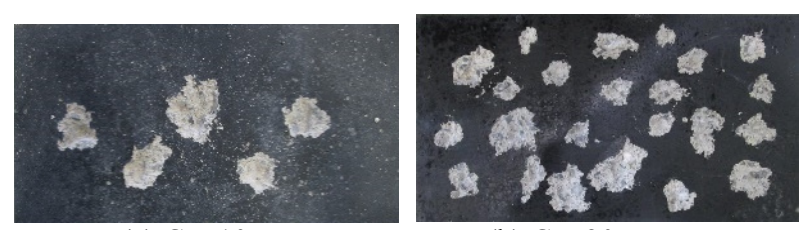

(a) $\mathrm{CH}-10 \mathrm{NM}$ (b) $\mathrm{CH}-20 \mathrm{NM}$

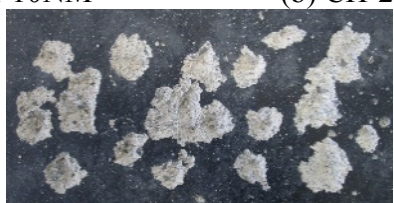

(c) $\mathrm{CH}-30 \mathrm{NM}$

Fig. 2 Examples of roughened concrete surface of shear-loading test specimens. 
Figures 2 and 3 show examples of the roughened concrete surfaces of the shear loading and shape measurement tests. After the concrete of each shear loading specimen was roughened, grouting mortar was placed on the joint surface. The smooth surface area was greased to minimize the influence of friction.

\subsection{Shape measurement of roughened surface}

The shape measurement setup is shown in Fig. 4. A laser displacement sensor was installed, and the three-dimensional shape data of the roughened surface were acquired by measuring the height of the unevenness with the laser displacement sensor scanning in the $x$ and $y$ directions along the guide rails as shown in Fig. 4. The measurement intervals were set at $0.04 \mathrm{~mm}$ in the $x$ and $y$ directions. Figure 5 shows the 3D scanner. This $3 \mathrm{D}$ scanner is a noncontact handy type scanner. It uses the pattern projection method for three-dimensional shape data acquisition. The light beam from the 3D

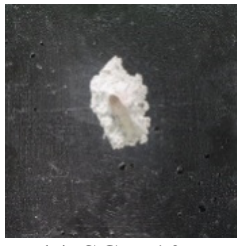

(a) $\mathrm{SCH}-10$

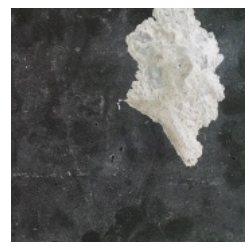

(b) $\mathrm{SCH}-20$

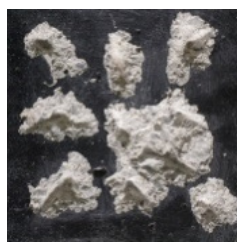

(c) $\mathrm{SCH}-30$
Fig. 3 Examples of roughened concrete surface of shape measurement test specimens.

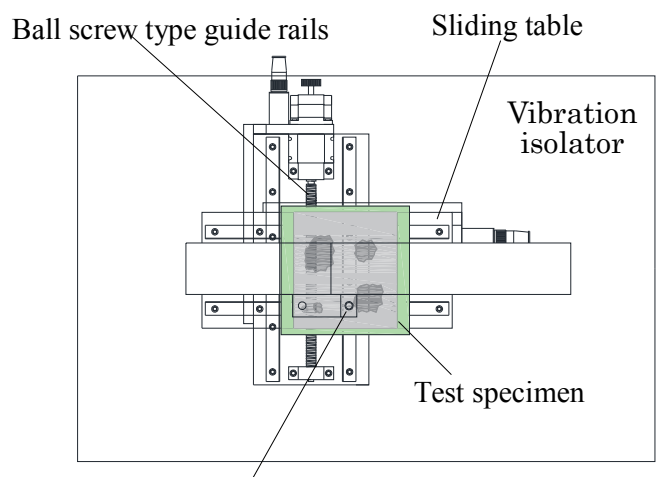

Laser displacement sensor Light spot diameter: $70 \mu \mathrm{m}$ Resolution: 0.002mm

Fig. 4 Shape measurement system.

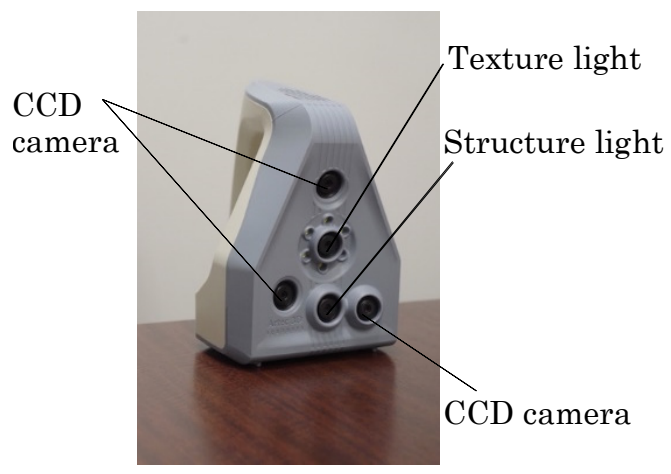

Fig. 5 3D scanner.
Table 4 Properties of laser displacement meter and 3D scanner.

\begin{tabular}{c|c|c}
\hline & $\begin{array}{c}\text { Laser displace- } \\
\text { ment sensor }\end{array}$ & 3D scanner \\
\hline \hline Measurement interval $(\mathrm{mm})$ & 0.04 & 0.1 \\
\hline Resolution $(\mathrm{mm})$ & 0.002 & 0.05 \\
\hline Measurement method & Automatic & Manual \\
\hline
\end{tabular}

scanner was reflected by the measured object and the time difference and the angle of the reflected light were analyzed to obtain the three-dimensional coordinate data.

The specimen was fixed and measured while the 3D scanner was moved manually. The measurement intervals in the $x$ and $y$ directions were $0.1 \mathrm{~mm}$, which was the minimum measurement interval of this $3 \mathrm{D}$ scanner. Table 4 lists the properties of the laser displacement sensor and the $3 \mathrm{D}$ scanner.

\subsection{Loading method of shear loading test}

The equipment for the shear loading test is illustrated in Fig. 6. As shown in the figure, 500-kN hydraulic jacks were used in the shear loading test to control the axial force and the horizontal load of the reversed cyclic loading. In the horizontal direction, reversed cyclic loading was applied with shear displacement $\delta$ controlled. The heights of the horizontal hydraulic jacks were the same as the joint surface of the specimen. The axial force was a constant load. Axial stress $\sigma$ was approximately $0.4 \mathrm{~N} / \mathrm{mm}^{2}$ in a previous study (Takase $e t$ al. 2012, 2014). Therefore, in previous shear loading tests of roughened concrete (Isozaki et al. 2017, 2018) and cylindrical shear-key (Abe et al. 2017), normal stresses were set to $0.48 \mathrm{~N} / \mathrm{mm}^{2}$. Accordingly, the constant normal stress was set to this value, and the loading beam was kept parallel during forced horizontal displacement.

The measurement method is shown in Fig. 7.

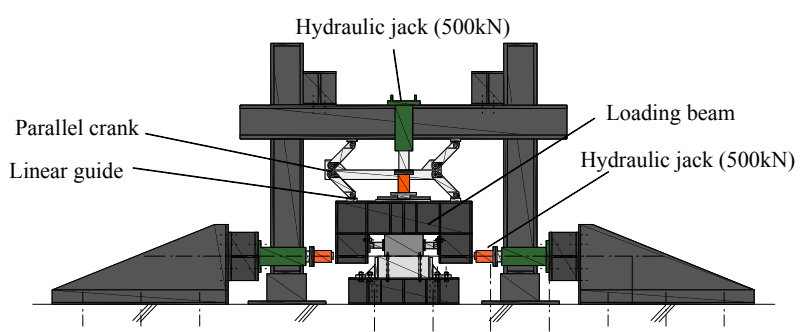

Fig. 6 Equipment for shear loading test.

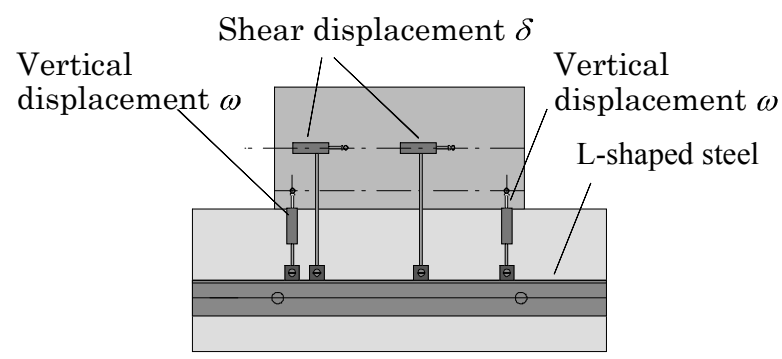

Fig. 7 Measurement method of shear-loading test. 
L-shaped steel was attached on the concrete, and displacement meters were attached on the L-shaped steel. Vertical displacement $\omega$ and relative shear displacement $\delta$ between the existing and strengthening members were measured.

\section{Results of shear loading test}

\subsection{Failure mode of specimen}

Figure 8 shows the failed state of a specimen after the shear loading test. Figure 9 shows the images of bearing failure and shear failure. In the case of shear failure, fracture surfaces of concrete or mortar are observed on the joint surface, as shown in Fig. 9(b). In Fig. 8, which shows the joint surface of $\mathrm{CH}-10 \mathrm{NM}$, these fracture surfaces were not observed, but damage on the side of the unevenness was observed.

Therefore, the fracture mode of $\mathrm{CH}-10 \mathrm{NM}$ was judged to be bearing failure. Although the fracture mode of most other specimens was bearing failure as in the case of CH-10NM, in specimens with $f_{C}=30 \mathrm{~N} / \mathrm{mm}^{2}$, the failure mode was a mixed mode consisting of both bearing failure and shear failure.

\subsection{Comparison of test results}

The test results of the $Q-\delta$ relations are shown in Fig. 10. In this figure, different figures are shown for different $r_{c r}$ values. Figure 11 shows the relationship between maximum load $Q_{\max }$ and $r_{c r}$ for $f_{C}=20 \mathrm{~N} / \mathrm{mm}^{2}$. Table 5 shows the test results at maximum load. The features of the $Q-\delta$ curve are: i) almost linear behavior up to the maximum load, ii) sharp reduction of the load after the peak load, and iii) constant load after failure. According to Fig. 11 and Table 5, the maximum load increases as $r_{c r}$ increases. Moreover, the maximum loads are largely the same regardless of roughened concrete depth.

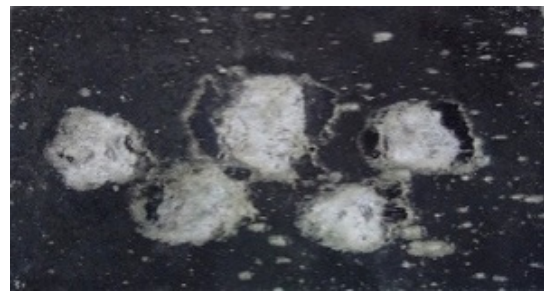

Fig. 8 Failure mode of specimen (CH-10NM).

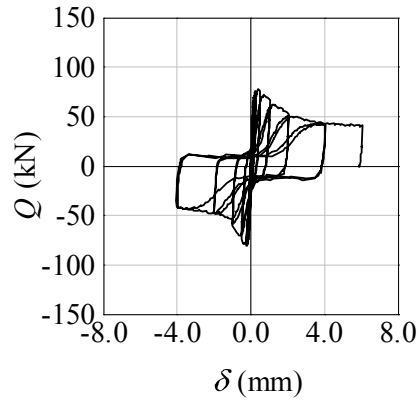

(a) $\mathrm{CH}-10 \mathrm{NM}$

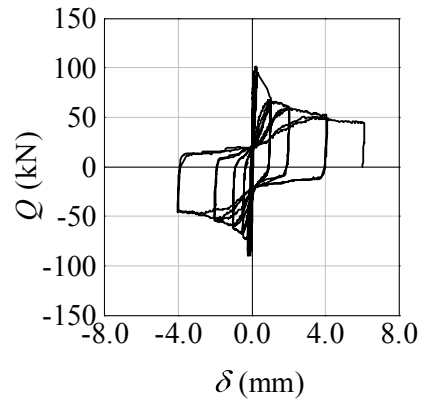

(b) $\mathrm{CH}-20 \mathrm{NM}$

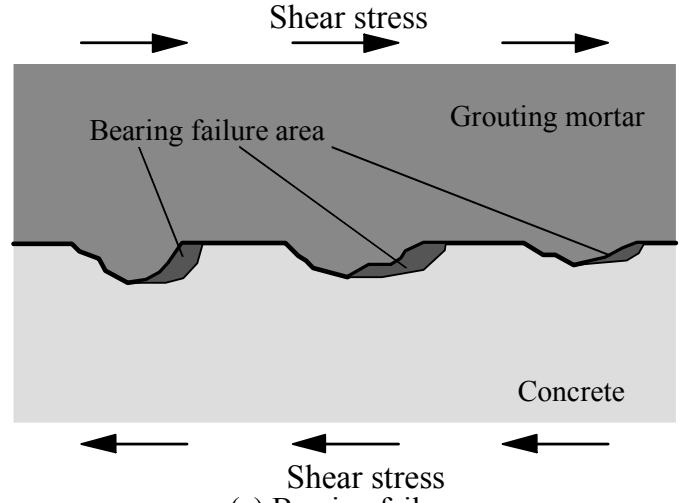

(a) Bearing failure Shear stress

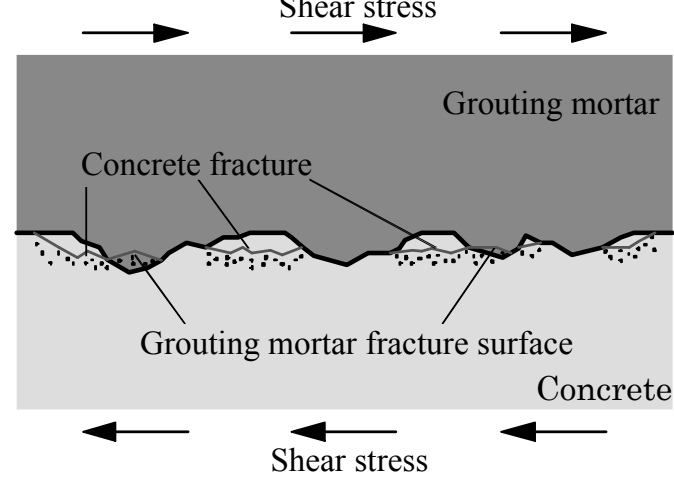

(b) Shear failure

Fig. 9 Images of failure modes.

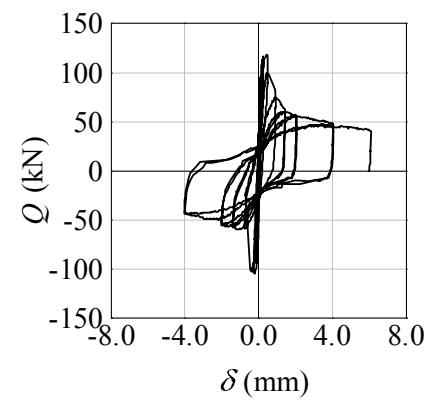

(c) $\mathrm{CH}-30 \mathrm{NM}$

Fig. 10 Examples of $Q-\delta$ relations. 
Table 5 Test results at maximum load.

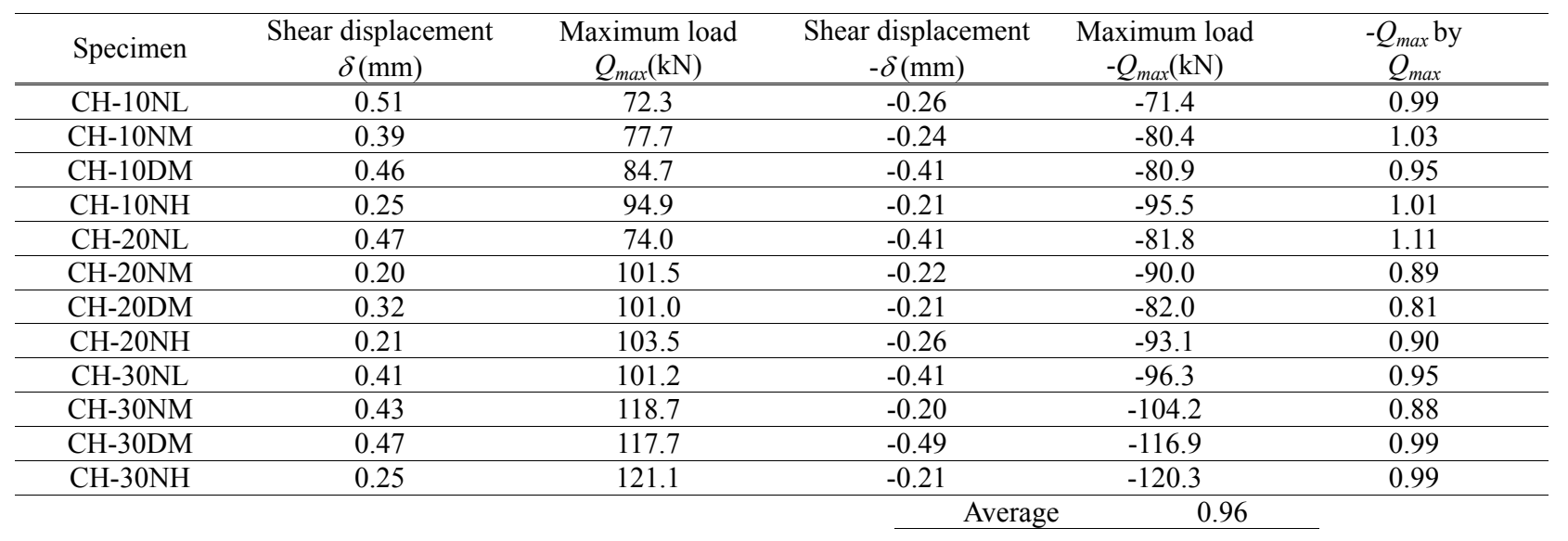

the figure in that earlier paper included data of another specimen, and therefore Fig. 12(b) in this paper should be regarded as the correct figure.

\section{Vertical projection area of roughened surface}

As mentioned in Section 1, bearing failure is thought to be influenced by the vertical projection area of unevenness. Therefore, in this section, the authors investigated the vertical projection area of the roughened surface. Because of an error in setting the specimens to the measurement setup, the three-dimensional shape measurement data were measured with the surface slightly inclined. First, the coordinate reference plane was calculated by the least-squares method using the flat sur-

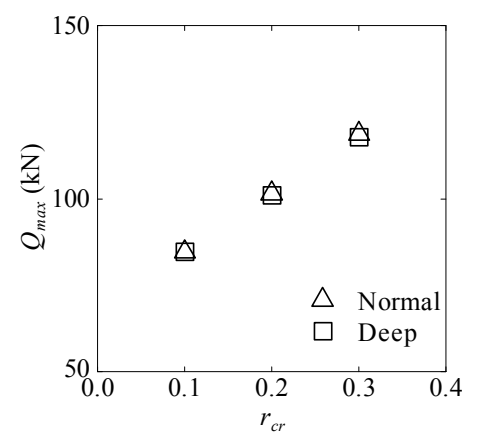

Fig. $11 Q_{\max }-r_{c r}$ relations.

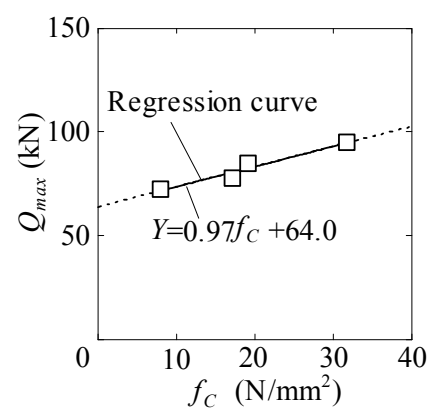

(a) $r_{c r}=0.1$

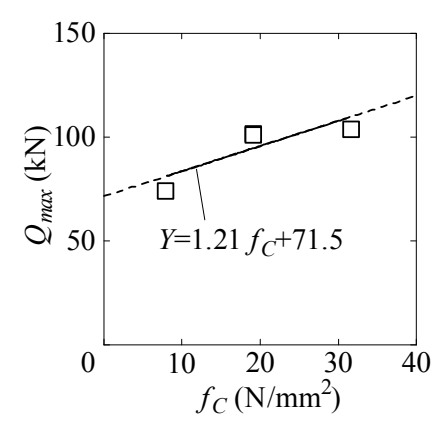

(b) $r_{c r}=0.2$ faces of the edges of the specimens. Then, the measurement data were converted to coordinate values, and the shape of the vertical projection area was analyzed.

Figure 13 shows the analysis method of the vertical projection area. Vertical projection area $\Delta A_{H i, j}$ of the local roughening between the point $i$ and point $i+1$ surfaces on the $j$ column is expressed by the following equation.

$$
\begin{aligned}
& \Delta A_{H i, j}=\Delta y\left|Z_{i, j}-Z_{i+1, j}\right| \\
& A_{H}=\sum_{j} \sum_{i} \Delta A_{H i, j}
\end{aligned}
$$

where, for the laser displacement sensor, $\Delta y=0.04 \mathrm{~mm}$, and for the $3 \mathrm{D}$ scanner, $\Delta y=0.1 \mathrm{~mm}$ from the measurement interval.

Figure 14 shows images of the joint surface and the definitions of symbols. As shown in Fig. 14, because there is extremely small roughness or noise values on the smooth part, these data are included in $A_{H}$. The vertical projection area on the smooth part is defined as $A_{H s m}$. Although it is thought that $A_{H s m}$ hardly affects shear strength, it cannot be ignored because the smooth part is larger than roughened area $A_{c r}$. Therefore, the authors removed $A_{H s m}$ from $A_{H}$. However, this calculation was very difficult, because neither the roughened part nor the smooth part could be determined solely through observation of the shape measurement data. Therefore, $A_{H s m}$

Fig. $12 Q_{\max }-f_{c}$ relations.

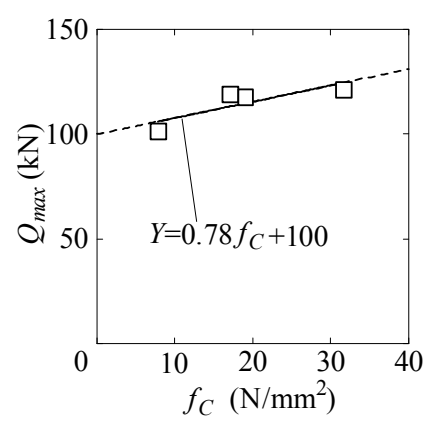

(c) $r_{c r}=0.3$ 
was removed using the following method. First, the smooth reference zone at the edge of the joint surface was defined. This zone is obviously the smooth part, and the horizontal area of this zone was defined as $A_{r f}$. Then, the vertical projection area of smooth reference zone $A_{H r f}$ was defined. Next, the relation between $A_{s m} / A_{H s m}$ and $A_{r f} / A_{H r f}$ could be expressed by the following equation.

$$
A_{s m}: A_{H s m}=A_{r f}: A_{H r f}
$$

Here, $A_{H r f}$ can be calculated, as well as $A_{H}$. Then, $A_{H s m}$ was expressed from Equation (2).

$$
A_{H s m}=\frac{A_{s m} \times A_{H r f}}{A_{r f}}
$$

Because $A_{s m}$ can be expressed using $r_{c r}, A_{H s m}$ was also described by the following equation.

$$
A_{H s m}=\frac{\left(1-r_{c r}\right) A_{j} \times A_{H r f}}{A_{r f}}
$$

Finally, area $\bar{A}_{H c r}$ with $A_{H s m}$ removed from $A_{H}$ could be calculated.

$$
\bar{A}_{H c r}=A_{H}-\frac{\left(1-r_{c r}\right) A_{j} \times A_{H r f}}{A_{r f}}
$$

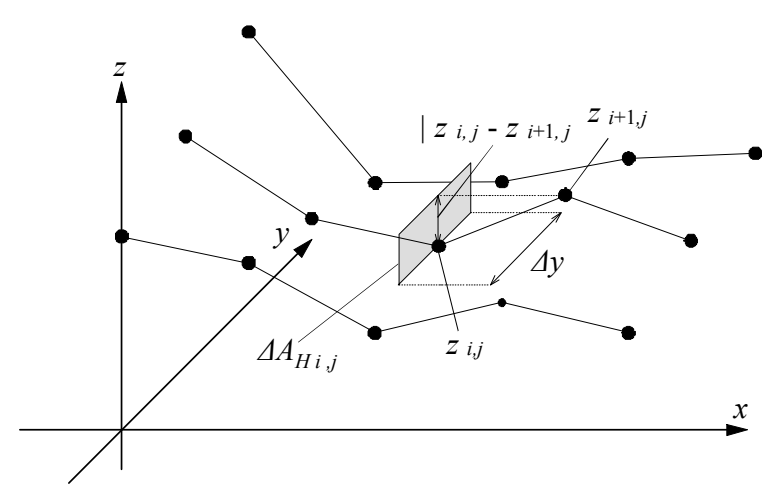

Fig. 13 Analysis method of $\Delta A_{H}$.

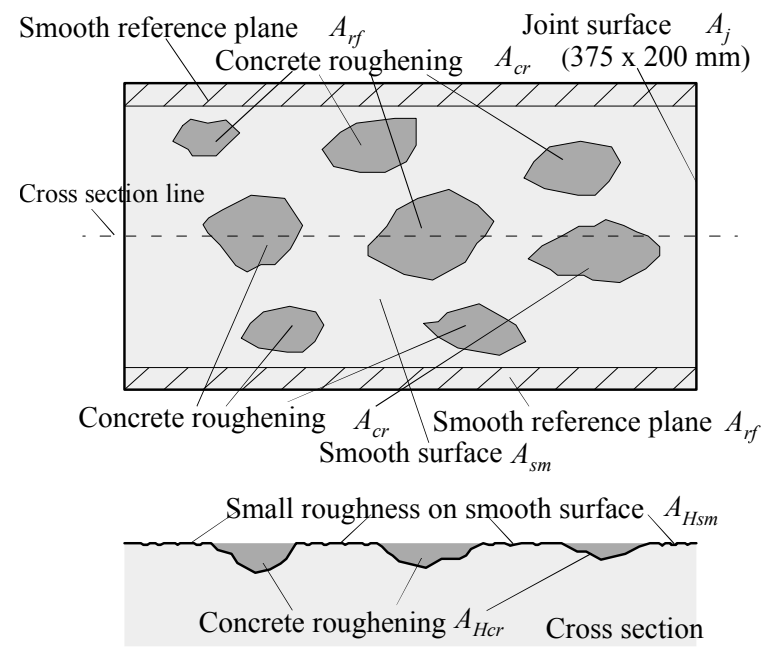

Fig. 14 Images of joint surface and definition of symbols.
Furthermore, because different surfaces contact the positive side and negative side when loading, $A_{H c r}$ was taken as half the value of $\bar{A}_{H c r}$.

$$
A_{H c r}=\bar{A}_{H c r} / 2
$$

Figure 15 shows the average of the vertical projection areas $A_{H}, A_{H c r}$, and $A_{H c r}$. In Table 2, the values of $A_{H c r}$ are shown. The shape properties of the roughened concrete created by the vibration drill are random. In this study, the average value of the shape properties of each $r_{c r}$ was used to quantitatively evaluate shear strength. By using the average data, the random values become more insignificant.

According to Fig. 15, comparison of vertical projection area $A_{H}$ or $A_{H c r}$ obtained with the laser displacement sensor and the 3D scanner shows that the values obtained by the $3 \mathrm{D}$ scanner are approximately $20 \%$ to $30 \%$ greater. This difference is believed to be due to the $3 \mathrm{D}$ scanner being moved manually or the presence of measured noise between neighboring points.

Further, Table 4 shows differences in resolution between the laser displacement sensor and the 3D scanner, which may be due in part to the same reason. The detailed investigation of the reasons is in order in the future. However, the tendencies of the relations between $A_{H}$ or $A_{H c r}$ and $r_{c r}$ are similar in both measurements. Therefore, although it is thought that the $3 \mathrm{D}$ scanner might not be suitable for measuring the detailed shape of roughened concrete, it is possible to apply this measuring method to estimate shear strength.

\section{Construction of shear-strength formula at bearing failure}

$Q_{\max }$ and $A_{H c r}$ are obtained from, respectively, the shear loading and the shape measurement tests. In this section, a bearing strength formula that can estimate $Q_{\max }$ is constructed.

\subsection{Basic equation of shear-strength formula (1) Shear-strength formula based on Fisher's equation}

In this study, the authors aimed to estimate bearing strength based on Fisher's shear-strength formula of a stud bolt (Ollgaard et al. 1971), which is cited as the bearing-strength formula of post-installed anchors in

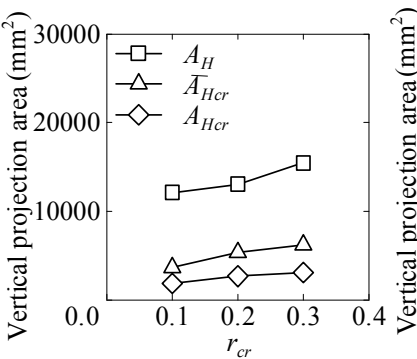

(a) Laser displacement sensor

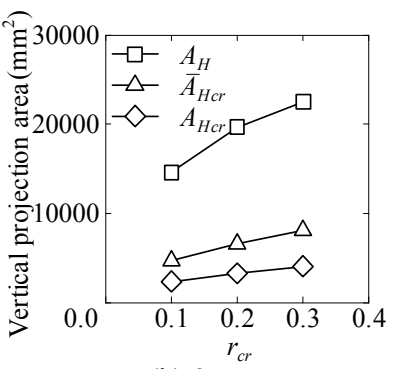

(b) 3D scanner
Fig. 15 Vertical projection areas. 
Table 6 Results of regression analysis.

\begin{tabular}{cccc}
\hline Measurement method & $K$ & $n 1$ & $n 2$ \\
\hline Laser displacement sensor & 19.3 & 0.23 & 0.01 \\
\hline 3D scanner & 9.40 & 0.10 & 0.27 \\
\hline
\end{tabular}

Japanese guidelines (JBDPA 2017) and the shear strength formula of the disk shear-key (Takase et al. 2012, 2014).

The shear strength was estimated by the function of $f_{C}^{0.3} \cdot E_{C}^{0.44}$ in this shear-strength formula. Shear strength $Q_{s 1}$ was proposed by taking $f_{C}$ and $E_{C}$ as parameters and further considering $A_{H c r}$.

$$
Q_{s 1}=K \cdot f_{C}^{n 1} \cdot E_{C}^{n 2} \cdot A_{H c r}
$$

where

$K:$ the test coefficient,

$n 1$ and $n 2$ : multipliers.

${ }_{l} Q_{s 1}$ and ${ }_{s} Q_{s 1}$ are the shear strength for the laser displacement sensor and the $3 \mathrm{D}$ scanner, respectively.

\section{(2) Test coefficient $K$ and estimation of indices $n 1$ and $n 2$}

Here, these coefficients were calculated with respect to the shear strength of each specimen using the least-squares method. Table 6 shows the results of regression analysis of three coefficients for measurement by laser displacement sensor and 3D scanner.

In addition, although shear failure was partially confirmed in $\mathrm{CH}-10 \mathrm{NH}$ to $\mathrm{CH}-30 \mathrm{NH}$ with $f_{C}=30 \mathrm{~N} / \mathrm{mm}^{2}$, these specimens were also taken into consideration, because the bearing failure is remarkable. From the analysis results in Table 6, ${ }_{l} K=19.3,{ }_{l} n 1=0.23$, and ${ }_{l} n 2=0.01$ for the laser displacement sensor, and ${ }_{s} K=9.4,{ }_{s} n 1=0.10$, and ${ }_{s} n 2=0.27$ for the $3 \mathrm{D}$ scanner.

(3) Estimation accuracy of shear strength formula From the coefficient calculated from Table 6, ${ }_{l} Q_{s 1}$ and ${ }_{s} Q_{s 1}$ were finally expressed by the following equations.

$$
\begin{gathered}
{ }_{l} Q_{s 1}=19.3 \cdot f_{C}^{0.23} \cdot E_{C}^{0.01} \cdot A_{H c r} \\
{ }_{s} Q_{s 1}=9.4 \cdot f_{C}^{0.10} \cdot E_{C}^{0.27} \cdot A_{H c r}
\end{gathered}
$$

Figure 16 shows a comparison of the test results with

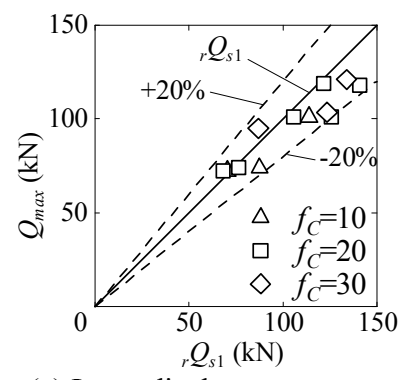

(a) Laser displacement sensor

Fig. 16 Comparison of test results with calculated results for bearing failure. the calculated results for bearing failure. The average values of the safety factors $\left(Q_{\max } /{ }_{l} Q_{s 1}\right)$ and $\left(Q_{\max } /_{s} Q_{s 1}\right)$ of all specimens are 1.06 and 0.97 , and the correlation coefficients are 0.91 and 0.93 , respectively. Moreover, because all specimens can be evaluated within the range of $\pm 20 \%$, it is possible to estimate $Q_{\max }$ with high accuracy by the proposed formula.

\subsection{Simplified shear-strength formula}

\section{(1) Basic equation}

As mentioned above, Fisher et al. (Ollgaard et al. 1971) constructed a shear-strength formula in which different indices are used for $f_{C}$ and $E_{C}$, by the function of $f_{C}^{0.3}$. $E_{C}{ }^{0.44}$. However, the shear-strength formula, which is a function of $\sqrt{f_{C} \cdot E_{C}}$, was also proposed as the design formula. Therefore, in this section, the authors propose shear strength $Q_{s 2}$, which is a function of $\left(f_{C} \cdot E_{C}\right)$.

$$
Q_{s 2}=K \cdot\left(f_{C} \cdot E_{C}\right)^{n} \cdot A_{H c r}
$$

where

$K$ : the test coefficient, $n$ : the multiplier.

${ }_{l} Q_{s 2}$ and ${ }_{s} Q_{s 2}$ : the shear-strength formula for the laser displacement sensor and the 3D scanner, respectively.

\section{(2) Estimation of test coefficient $K$ and index $n$}

Figure 17 shows the relations of $Q_{\max }-f_{C} \cdot E_{C} \cdot A_{H c r}$, and Fig. 18 shows $Q_{\max }-\left(f_{C} \cdot E_{C}\right)^{n} \cdot A_{H c r}$ relations. Figure 17 shows a regression curve that is determined by the least-squares method. As a result, $Y=9.5 X^{0.17}$ and $Y=$ $9.0 X^{0.17}$ are obtained for, respectively, the laser displacement sensor and the 3D scanner.

From these results, both ${ }_{l} n$ and ${ }_{s} n$ are 0.17 . Subsequently, in Fig. 18, a regression curve is obtained from the least-squares method, and $Y=4.2 X$ and $Y=3.4 X$ are obtained for, respectively, the laser displacement sensor and the $3 \mathrm{D}$ scanner. Thus, ${ }_{l} K=4.2$ and ${ }_{s} K=3.4$.

\section{(3) Estimation accuracy of shear-strength formula} From the coefficients calculated from Figs. 17 and 18, ${ }_{l} Q_{s 2}$ and ${ }_{s} Q_{s 2}$ are finally expressed by the following equations.

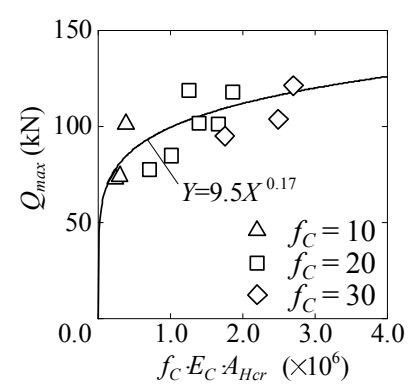

(a) Laser displacement sensor

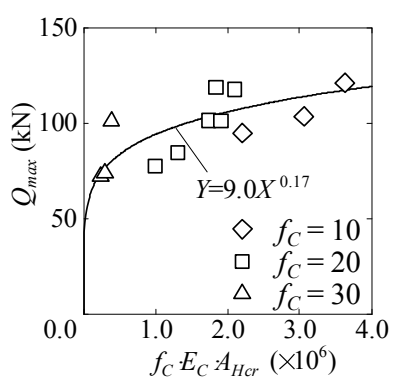

(b) $3 \mathrm{D}$ scanner
Fig. $17 Q_{\max }-{ }_{C} \sigma_{B} \cdot E_{C} \cdot A_{H c r}$ relations. 


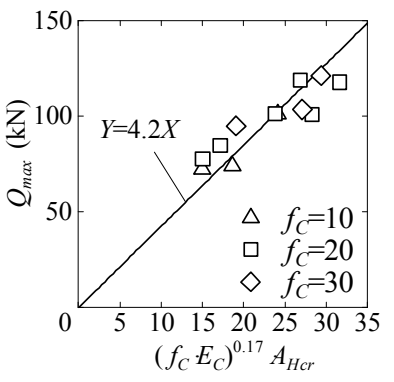

(a) Laser displacement sensor

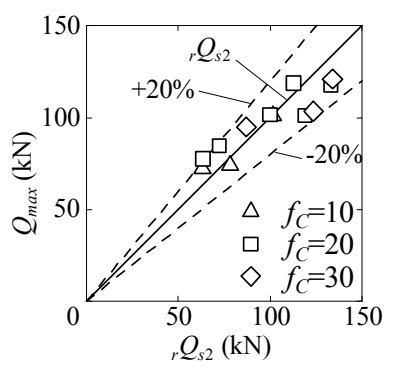

(a) Laser displacement sensor

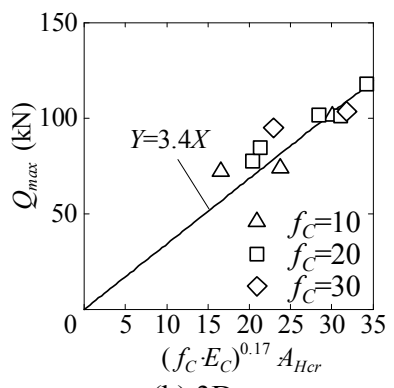

(b) $3 \mathrm{D}$ scanner
Fig. $18 Q_{\max }-\left(f_{C} \cdot E_{C}\right)^{n} \cdot A_{H c r}$ relations.

Fig. 19 Comparison of test results with calculated results for bearing failure (when using simplified formula).

$$
\begin{gathered}
{ }_{l} Q_{s 2}=4.2 \cdot\left(f_{C} \cdot E_{C}\right)^{0.17} \cdot A_{H c r} \\
{ }_{s} Q_{s 2}=3.4 \cdot\left(f_{C} \cdot E_{C}\right)^{0.17} \cdot A_{H c r}
\end{gathered}
$$

Figure 19 shows a comparison of the test results with the calculated results. The average values of the safety ratio $\left(=Q_{\max } / l Q_{s 2}\right)$ and $\left(=Q_{\max } / s Q_{s 2}\right)$ of all specimens from Equations (11) and (12) are 0.98 and 0.97, respectively. Moreover, the correlation coefficients are 0.93 and 0.95 , respectively. Because all specimens can be evaluated within the range of $\pm 20 \%$, it is possible to estimate $Q_{\max }$ with high accuracy by the proposed formula.

As mentioned, using the material properties of the concrete and vertical projection area, new shear strength formulas of $Q_{s 1}, Q_{s 2}$ were proposed. Although there were no correlations among the three coefficients in $l_{l} Q_{s 1}$ and ${ }_{s} Q_{s 1}$ by the difference in measurement methods, the coefficient $K$ of ${ }_{l} Q_{s 2}$ and ${ }_{s} Q_{s 2}$ showed a difference. This difference is thought to be due to the difference in the vertical projection area analysis results. However, even if the measurement method were different, there would not be much difference in the correlation coefficient of the shear strength and the accuracy of the estimation. Thus, 3D scanners are found to be equally applicable to the estimation of shear strength as laser displacement sensors.

\section{Conclusion}

This study focused on the roughened concrete of a joint surface between an existing member and a strengthen- ing member, and a shear loading test, shape measurement, and shape analysis were conducted. Two types of measurement method were applied. From the test results, a formula of shear strength at bearing failure was obtained. This formula approximated the test results reasonably well. The findings are listed below.

1) In the specimen of $f_{C}=30 \mathrm{~N} / \mathrm{mm}^{2}$ and $r_{c r}=0.1$ to 0.3 , the failure modes were a mixed mode in which both bearing failure and shear failure occurred. However, in other specimens with $r_{c r}=0.1$ to 0.3 , only bearing failure occurred.

2) The vertical projection area of the roughened concrete increased as $r_{c r}$ increased.

3) Comparing vertical projection area $A_{H c r}$ by the laser displacement sensor with that by the $3 \mathrm{D}$ scanner, $A_{H c r}$ values by the $3 \mathrm{D}$ scanner were $20 \%$ to $30 \%$ greater than those by the laser sensor. It is thought that manual measurement and the difference in resolution influenced measurement accuracy.

4) The shear-strength formulas were constructed using the vertical projection area. Then, comparing the calculation results with the test results, the test results made it possible to estimate with high accuracy.

The proposed formula does not consider the influence of axial force. Therefore, investigations into the influence of axial force and the measurement accuracy of 3D scanners are planned in the future.

\section{References}

Abe, T., Hiwatashi, T., Kubota, M., Takase, Y. and Katori, K., (2017). "Formula for shear strength of cylindrical shear-key applied seismic retrofitting." In: Proceedings of the 16th World Conference on Earthquake Engineering, Santiago Chile, Article Number: 611.

Isozaki, T., Takase, Y., Abe, T. and Katori, K., (2017). "Fundamental study on shear resistance of roughened concrete surface for existing members." Proceedings of the Japan Concrete Institute, 39(2), 919-924. (in Japanese)

Isozaki, T., Musya, U., Takase, Y., Abe, T., Sakamoto, K., Hiwatashi, T. and Katori, K., (2018). "Mechanical model of shear stress transfer of roughened concrete surface for R/C existing member." Proceedings of Computational Modeling of Concrete Structures, 973-982.

JBDPA, (2017). "Seismic evaluation and retrofit." Tokyo: The Japanese Building Disaster Prevention Association.

Nakano, K. and Matsuzaki, Y., (2001). "Additional method of shear resistances in precast concrete connections." J. Struct. Constr. Eng. (Transactions of AIJ), 66(550), 151-158. (in Japanese)

Maekawa, K. and Qureshi, J., (1997). "Stress transfer across interfaces in reinforced concrete due to aggregate Interlock and dowel action." Journal of Materials, Concrete Structures and Pavements, JSCE, 
34(557), 159-172.

Musya, U., Katagiri, Y., Takase, Y., Abe, T., Sakamoto, K., Hiwatashi, T. and Katori, K., (2019). "Supported strength formula of roughened concrete using shape measurement value by 3D-scanner." AIJ Journal of Technology and Design, 25(59), 55-60.

Ollgaard, J. G., Slutter, R. G. and Fisher, J. W., (1971). "Shear strength of stud connectors in lightweight and normal-weight concrete." AISC Engineering Journal, (4), 55-64.

Rahal, K., (2010). "Shear-transfer strength of reinforced concrete." Article in ACI Structural Journal, 107(S41), 419-426.

Satoh, A., Kanji, K. and Ishiyama, S., (2014). "Experimental study on major parameters of fractography for concrete." J. Struct. Constr. Eng. (Transactions of AIJ), 79(698), 437-444. (in Japanese) Takase, Y., Abe, T., Itadani, H., Satoh, T., Onaka, A., Kubota, M. and Ikeda, T., (2014). "Estimation method of horizontal capacity of joint fracture for retrofitted frame using disk shear-key-Study on shear-key consisted of steel disk and anchor bolt for earthquake retrofitting." J. Struct. Constr. Eng. (Transactions of AIJ), 79(698), 507-515. (in Japanese)

Takase, Y., Ikeda, T., Yagisawa, Y., Satoh, T., Imai, K., Onaka, A., Itadani, H., Abe, T. and Kubota, M., (2012) "Development of shear-key consisted of steel disk and anchor bolt for seismic retrofitting." In: Proceedings of 15th World Conference on Earthquake Engineering, Lisboa Portugal, Article Number: 2617. 